\title{
Switchgrass PvDREB1C plays opposite roles in plant cold and salt tolerance in transgenic tobacco
}

\author{
Wuwu Wen', Zheni Xie', Guohui Yu', Chengliang Zhao', Jing Zhang ${ }^{1}$, Linkai Huang ${ }^{2}$, Bin Xu ${ }^{1 *}$ (D) and Bingru Huang ${ }^{3}$
}

\begin{abstract}
Background: The C-repeat-binding factors/DRE-binding factors (CBF/DREBs) comprise a key transcription factor family involved in plant stress tolerance. Yet, there is limited information about switchgrass DREB genes and their functional roles.

Results: In this study, four cold-inducible PvDREB1s were identified from switchgrass (Panicum virgatum), among which PVDREB1C was the one responded to cold stress later than the other three PVDREB1s. Yet, ectopic overexpression of PVDREBTC led to significantly compromised, instead of improved cold tolerance in transgenic tobacco. On the other hand, PVDREB1C was transcriptionally down-regulated in response to salt stress, but overexpression of PVDREB1C improved plant salt tolerance in transgenic tobacco. The improved salt tolerance was associated with increased $\mathrm{K}^{+} / \mathrm{Na}^{+}$ratio and $\mathrm{Ca}^{2+}$ content, higher cellular osmotic potential, and activation of stressrelated functional genes in the leaves of transgenic plants under salt stress.

Conclusions: The current results implied that PVDREB1C played opposite roles in plant cold and salt tolerance. Although DREB1s were known as positive stress regulators, particular attentions shall be paid to their potential negative regulatory role(s).
\end{abstract}

Keywords: Switchgrass, DREB/CBF, Dual function, Cold, Salt, Stress

\section{Background}

Switchgrass (Panicum virgatum) is a perennial, $\mathrm{C}_{4}$ tall grass used for biofuel and forage feedstock production, water and soil conservation, as well as habitat restoration [1-3]. Switchgrass is known for its wide adaptation to diverse and relatively harsh environment [4]. However, genetic improvement of switchgrass is highly desirable to successfully establish switchgrass in marginal lands with minimal biomass sacrifice and little cost of resource and labor inputs.

The C-repeat-binding factors/DRE-binding factors (CBF/ DREBs) constitute an indispensable regulatory network for plant tolerance against abiotic stresses (e.g. cold, drought and salinity, etc.) [5]. DREBs primarily function through transactivating the expression of downstream functional genes through binding to the C-repeat/dehydration responsive (CRT/DRE) cis-elements [6]. Previous studies revealed

\footnotetext{
* Correspondence: binxu@njau.edu.cn

${ }^{1}$ College of Agro-grassland Science, Nanjing Agricultural University, Nanjing

210095, People's Republic of China

Full list of author information is available at the end of the article
}

that CBFs play important roles in plant cold tolerance through the IEC1-CBF regulon to activate the expression of downstream cold-responsive genes [7]. CBF/DREBs (e.g. OsDREB1D and OsDREB1F) were also reported to positively regulate plant salt and drought tolerances $[8,9]$. Despite the importance of DREB family genes in plant stress tolerance, there is limited information about switchgrass DREB genes and their functional roles.

The objective of this study was to analyze the biological function of a DREB1 gene for its potential use in switchgrass genetic improvement. The cloned switchgrass DREB1C was up-regulated by cold stress but down-regulated by salt and osmotic stress. Yet, overexpression of PvDREB1C in transgenic tobacco led to compromised cold tolerance, but improved salt tolerance with lower $\mathrm{Na}^{+} / \mathrm{K}^{+}$ratio and higher reactive oxygen scavenging enzyme activities under salt stress. 


\section{Results}

\section{Four switchgrass DREB1 genes transcriptionally} responsive to cold exposure

In searching for CBFs/DREB1s involved in cold tolerance in switchgrass, four rice cold-responsive DREB1s [i.e. OsDREB1A (Os09g0522200), OsDREB1B (Os09g0522000), OsDREB1C (Os06g0127100), OsDREB1G (Os02g0677300) $[10,11]$ were used to search corresponding orthologs against the switchgrass genome database (Panicum virgatum v1.1, DOE-JGI) using BLAST. Seven orthologous switchgrass $P v D R E B 1$ s were found according to their corresponding orthologous genes in rice. According to the phylogenetic analysis (Fig. 1a), these PvDREB1s were named as PvDREB1A-1/-2 (Pavir.J03891.1 \& Pavir.Ba01280.1), PvDREB1B-1/-2 (Pavir.J19655.1 \& Pavir.Ba01283.1), PvDREB1C (Pavir.J35991.1), and PvDREB1G-1/-2 (Pavir.Ab02685.1 \& Pavir.Aa00912.1). Switchgrass 'Alamo' is an allotetraploid with two closely related chromosomal sets $[12,13]$. PvDREB1G-1 and -2 were paralogous genes in corresponding homeologous chromosomes $1 \mathrm{~b}$ and 1a, respectively (switchgrass genome from JGI: Panicum virgatum v4.1). Although the chromosome locations of PvDREB1A-1and PvDREB1B-2 were not determined yet, these two paired $P v D R E B 1 \mathrm{~s}$ were likely derived from the allotetraploidy event of switchgrass as well $[12,13]$.

To verify whether these $P v D R E B 1 s$ were cold-inducible genes, we exposed non-acclimatized switchgrass to $4{ }^{\circ} \mathrm{C}$. The three paired genes shared highly similar nucleotide sequence identity that the paired genes could not be discriminated from each other using real-time PCR. Therefore, the detected transcript levels of $P v D R E B 1 A$, $P v D R E B 1 B$, or PvDREB1G should be the combination of their respective paralogous genes (e.g. the detected transcript level of $P v D R E B 1 A$ should be comprised of both PvDREB1A-1 and PvDREB1A-2 as shown in Fig. 1). As predicated, these four $P v D R E B 1$ s all responded to low temperature treatment, yet their expression patterns differed. $P v D R E B 1 A$ and $P v D R E B 1 G$ were quickly induced by the cold treatment that their transcripts dramatically increased over 100 times within $0.5 \mathrm{~h}$ and reached its peak level after 1 or $4 \mathrm{~h}$ respectively. The expression level of PVDREB1B quickly decreased after $0.5 \mathrm{~h}$ of cold treatment, then slowly increased and reached its peak after $4 \mathrm{~h}$.

$P V D R E B 1 C$ was the one responded relatively late to cold treatment, and its transcripts accumulated after $2 \mathrm{~h}$ - of treatment, reached its peak after $4 \mathrm{~h}$ and decreased thereafter. In particular, PvDREB1C was also transcriptionally suppressed by $\mathrm{NaCl}$ and drought treatments within $0.5 \mathrm{~h}$ and decreased to its lowest level 2$4 \mathrm{~h}$ after the corresponding stress treatment (Fig. 1f, g). Since most DREB1s genes were transcriptionally upregulated in response to abiotic stresses [5], it was uncommon to see that the transcription of PvDREB1C was decreased under salt and drought stresses. Therefore, the function of PvDREB1C was further investigated.

\section{Ectopic overexpression of PvDREB1C in tobacco negatively affected its tolerance against cold stress}

Stable transgenic tobacco plants were generated to further characterize the function of PvDREB1C. As shown in Fig. 2, three transgenic lines with varied expression levels of $P v D R E B 1 C$ were used for analysis. These transgenic plants did not show apparent phenotypic alterations compared to wildtype (WT) plants under the optimum condition. However, the transgenic plants showed higher electrolyte leakage (EL) rates under chilling stress $\left(4^{\circ} \mathrm{C}\right)$ (Fig. 3a), and had significantly lower survival rates than those of WT when exposed to freezing stress $\left(-4{ }^{\circ} \mathrm{C}\right)$ (Fig. 3b-c), demonstrating that overexpression of $P v D R E B 1 C$ led to compromised cold tolerance.

\section{PvDREB1C improved plant salt tolerance in tobacco}

Since the expression of $P v D R E B 1 C$ was inhibited by PEG and $\mathrm{NaCl}$ treatments, we further tested whether transgenic plants had altered drought and salt tolerance. Unchanged drought tolerance was observed with the transgenic plants (data not shown), while significantly improved salt tolerance was recorded. As shown in Fig. 4, the transgenic plants had significantly bigger plant sizes with higher fresh weight (FW) and plant height than those of the WT after 25 days of salt treatment by watering with $200 \mathrm{mM} \mathrm{NaCl}$.

Plants respond to salinity stress through two distinct phases: ion-specific and osmotic-changing phases [14]. Both phases were checked at physiological and gene expression levels comparing the transgenic with the WT plants. Without salt treatment, the transgenic plants had comparable contents of $\mathrm{Na}^{+}$and $\mathrm{K}^{+}$in both leaves and roots with the WT plants; under salt stress, the transgenic plants demonstrated significantly less $\mathrm{Na}^{+}$ contents and $\mathrm{Na}^{+} / \mathrm{K}^{+}$, and higher $\mathrm{Ca}^{2+}$ contents in leaves but not in roots (Fig. 5), suggesting that overexpressing $P v D R E B 1 C$ altered the sodium transportation from root to shoot.

At the osmotic-changing phase, the transgenic plants also demonstrated significantly higher osmotic potential, and higher activities of ROS-scavenging enzymes [ascorbate peroxidase (APX), superoxide dismutase (SOD) and peroxidase (POD)], lower $\mathrm{H}_{2} \mathrm{O}_{2}$ contents and smaller EL values (reflecting better cell membrane integrity) than those in the WT under salt stress (Fig. 6).

\section{Overexpression of PvDREB1C activated stress-related functional genes}

Relative expression levels of ten downstream functional genes encoding for $\mathrm{Na}^{+} / \mathrm{K}^{+}$transporters, ROS-scavenging 

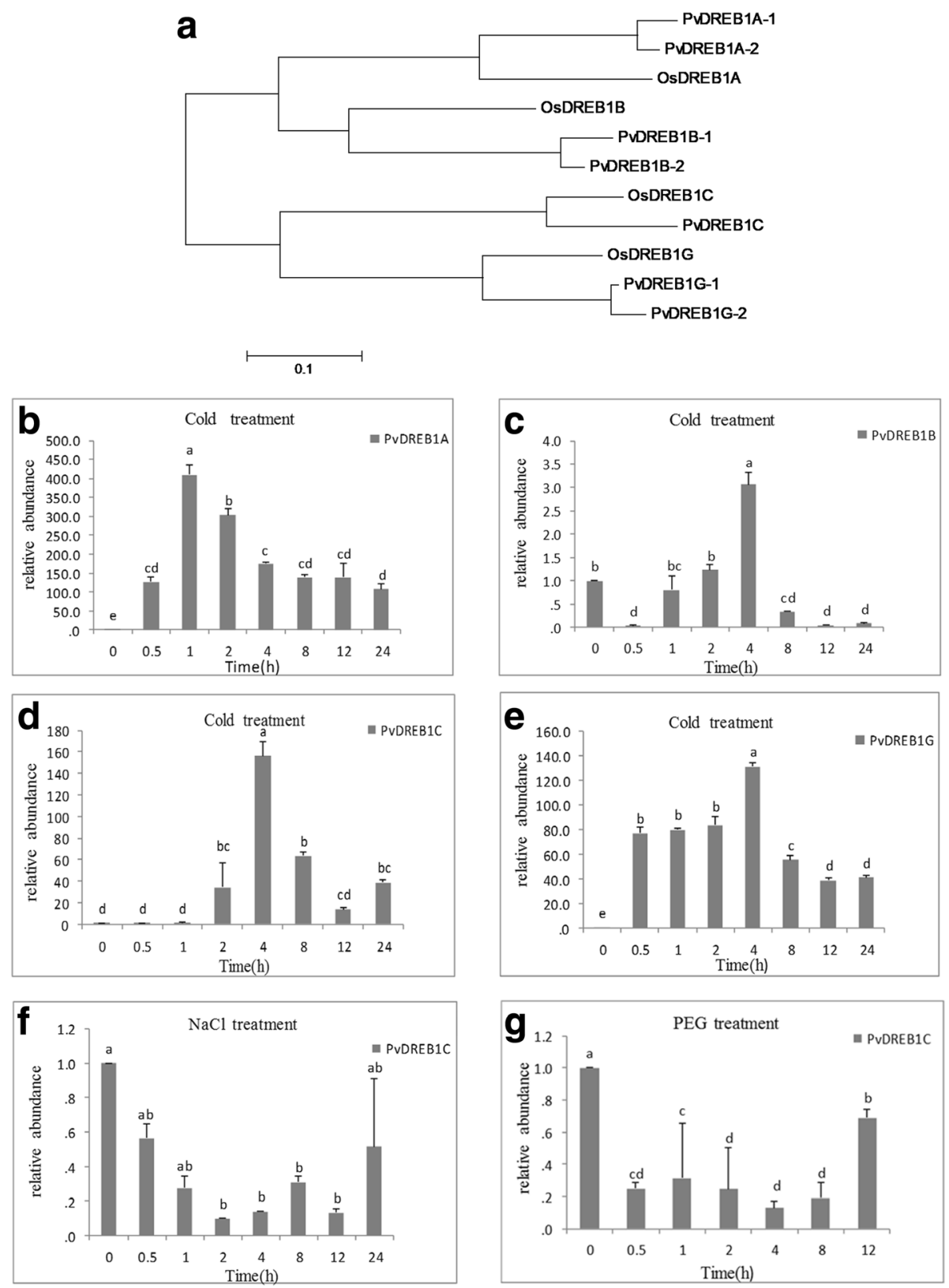

Fig. 1 Phylogenetic analysis and relative expression of four cold-inducible PVDREB1s. a The Neighbor-Joining tree was built using MEGA6 software. The optimal tree is drawn to scale, with the sum of branch length $=1.99584622$ is shown. $\mathbf{b}$-e Expression of DREB1s in response to low temperature $\left(4^{\circ} \mathrm{C}\right)$. $\mathbf{f}-\mathbf{g}$ PVDREB1C was transcriptionally suppressed by $250 \mathrm{mM} \mathrm{NaCl}$ or PEG-6000 (20\%, W/V). Data are represented as mean $\pm \mathrm{SE}(n=3)$, and different letters above bars indicate a significant difference at $P<0.05$

enzymes, dehydrins and polyamines were further checked (Fig. 7). And the qRT-PCR results showed that relative expression levels of one $\mathrm{Na}^{+} / \mathrm{K}^{+}$transporter gene (NtNHX4), two ROS-scavenging enzyme genes (NtSOD \&NtPOD), and a dehydrin-encoding gene (NtERD1OB) were significantly higher in the transgenic plant than those in the WT under salt stress, while those of NtSOS1, NtcAPX, NtPAO, and $\mathrm{NtCuAO} 2$ were largely unchanged.
It is known that DREB1s preferentially bind to DRE ciselement (ACCGAC or GCCGAC) to activate their downstream genes. The presence of at least one ACCGAC DRE cis-element in $-2 \mathrm{~Kb}$ promoter regions of $\overline{N t S O D}, \mathrm{NtPOD}$, and $N t E R D 10 B$ were identified (see Additional file 1), suggesting that these genes were among the direct target genes of PvDREB1C. To further understand the binding preference of PvDREB1C to the two types of DRE cis- 

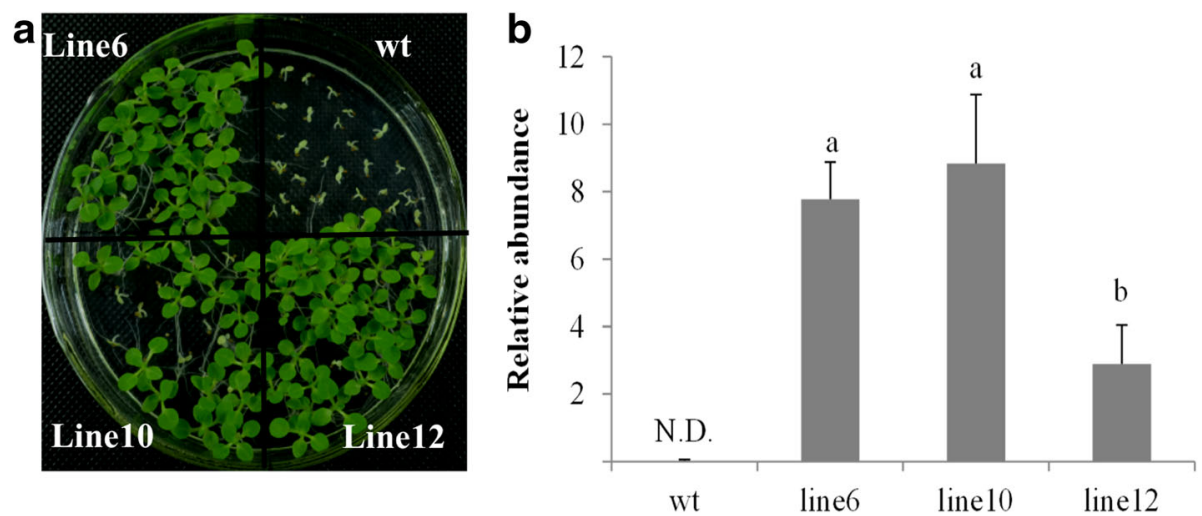

Fig. 2 Verification of transgenic lines used in this study. a T2 seeds germinated in selective medium containing $15 \mathrm{mg} \cdot \mathrm{L}^{-1}$ bialaphos. $\mathbf{b}$ Relative expression of the transgene, PVDREB1C, in three transgenic lines. Data are represented as mean $\pm \mathrm{SE}$, and different letters above bars indicate a significant difference at $P<0.05$

elements, we generated mutant $r d 29 A$ promoters with one ACCGAC and four GCCGAC (rd29A $\mathrm{A}_{\text {pro-1A4G }}$ ), or with five GCCGAC but no ACCGAC (rd29A $\left.\mathrm{A}_{\text {pro-0A5G }}\right)$ as illustrated in Fig. 8 (sequences presented in Additional file 1). Cotransformation of $35 \mathrm{~S}_{\text {pro }}: P v D R E B 1 C$ (effector) and $r d 29 A-$ pro:UidA (reporter) in $N$. benthamiana showed that PvDREB1C activated the expression of GUS only in the presence of ACCGAC in the mutant $r d 29 A$ promoter (Fig. 8), suggesting that PvDREB1C preferentially activated those promoters with ACCGAC as the core DRE cis-element.

\section{Discussion}

The CBF/DREB1 transcription factors constitute important signaling components in plant tolerance to various
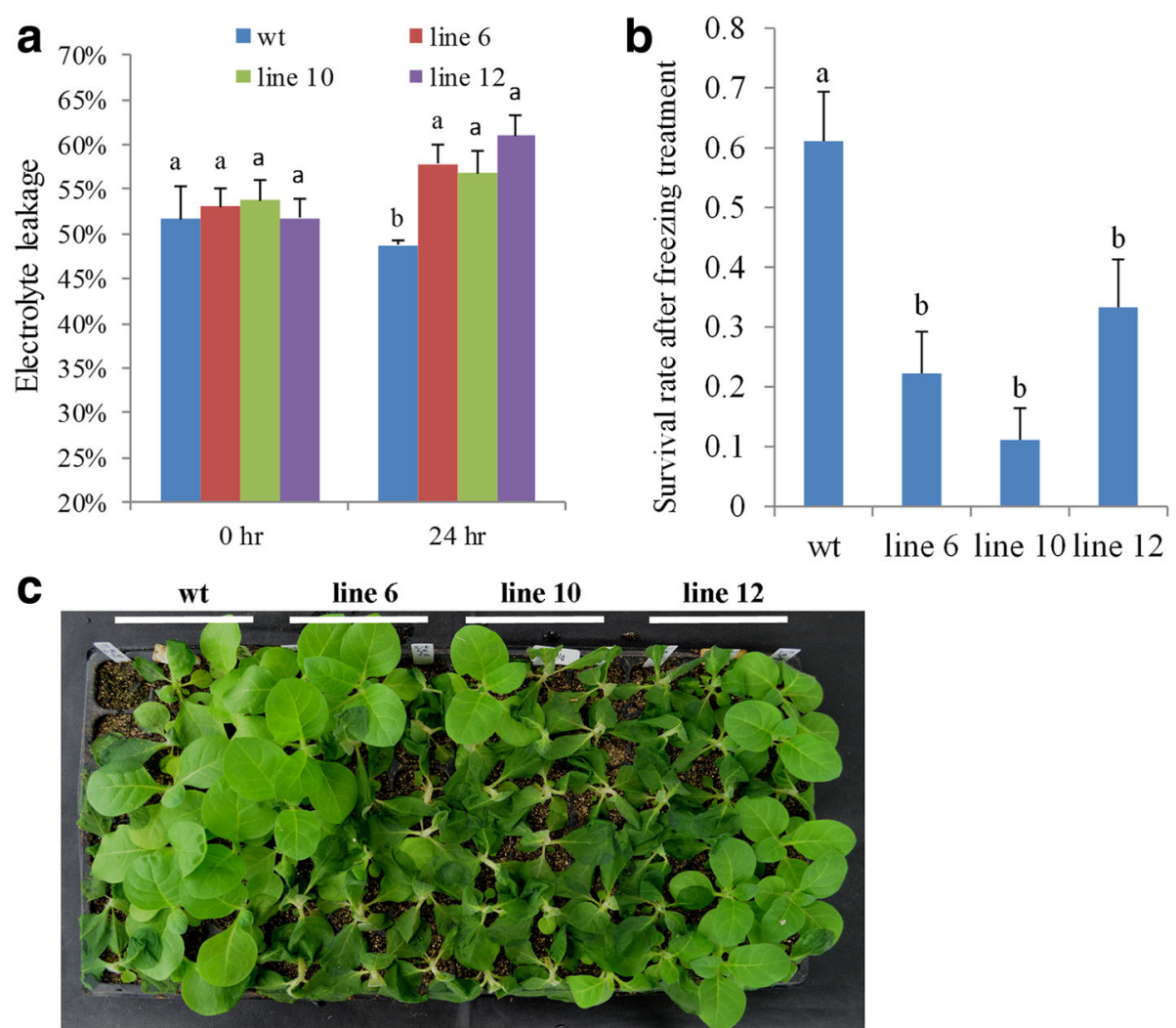

Fig. 3 Overexpressing PVDREB1C compromised the cold tolerance in tobacco. a Electrolyte leakage rates of tobacco exposed to $4{ }^{\circ} \mathrm{C}$ for $24 \mathrm{~h}$. b, $\mathbf{c}$ Survival rate and phenotype of tobacco 2 days after $-4{ }^{\circ} \mathrm{C}$ treatment for $3 \mathrm{~h}$. Data are means of 18 plants of each line with two independent experimental repeats. Data are represented as mean $\pm \mathrm{SE}$, and different letters above bars indicate a significant difference at $\mathrm{P}<0.05$ 

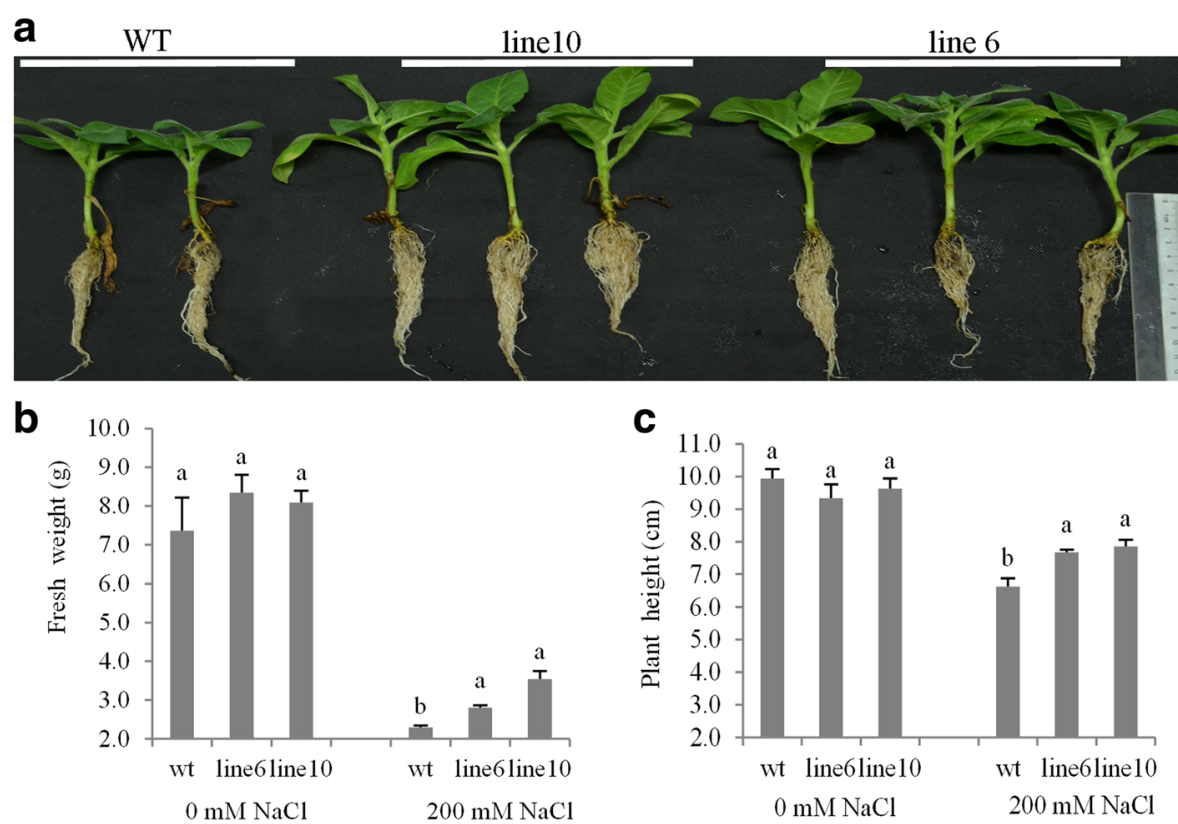

Fig. 4 Transgenic PVDREBIC tobacco showed improved tolerance to salt stress. a-c The PVDREBIC transgenic plants showed better performance after 25 days of $200 \mathrm{mM} \mathrm{NaCl}$ treatment: phenotypes $\mathbf{a}$, fresh weight $\mathbf{b}$ and plant height $\mathbf{c}$ of transgenic and wildtype plants. Data are represented as mean \pm SE $(n=6)$, and different letters above bars indicate a significant difference at $P<0.05$

abiotic stresses [15]. In most cases, positive regulatory roles of CBF/DREB1 in plant abiotic stresses were documented [15], and their biological functions were often positively associated with their transcriptional responses to abiotic stresses, such as DREB1A/CBF3 \& DREB1B/ $C B F 1$ in Arabidopsis [6, 16], and OsDREB1A [11] and OsDREB1B [17] in rice. One exception was CBF2/ $D R E B 1 C$ in Arabidopsis, which suppressed CBF1 \& CBF3 and thereby negatively affected plant cold tolerance [18]. Yet, overexpressing the Arabidopsis DREB1C improved plant drought tolerance [19], suggesting that CBF2/ DREB1C played opposite roles in orchestrating plant tolerance against cold and drought stresses. In this study, we initially identified $P v D R E B 1 C$ as a cold-inducible gene, but found that overexpressing PvDREB1C lead to compromised plant cold tolerance, unchanged drought tolerance and improved salt-tolerance, suggesting that both PvDREB1C and Arabidopsis DREB1C had opposite functions in regulating plant tolerance against different types of abiotic stress. Although DREB1s were known as positive stress regulators, particular attentions shall be paid to their potential negative regulatory role(s).

Plants employ different strategies to cope with cold and salt stresses. Yet, crosstalk between these abiotic stress responses via common signaling molecules (e.g. ABA and $\mathrm{Ca}^{2+}$ ) or pathways was recorded [20]. Chilling (above $0{ }^{\circ} \mathrm{C}$ ) primarily causes the damage of cell membrane system, inhibition of photosynthesis as well as oxidative stress, while freezing (below $0{ }^{\circ} \mathrm{C}$ ) exerts additional mechanical damage due to the formation of ice crystals within cells or in intercellular spaces [21]. At the molecular level, cold is sensed by membrane proteins such as COLD1, leading to cytosolic $\mathrm{Ca}^{2+}$ signal to activate MAP kinase cascade, that phosphorylate transcription factors (e.g. ICE1) [22, 23], and the activated ICE1 rapidly induces the expression of CBF/DREB1s to trans-activate the expression of downstream coldresponsive genes [7]. $\mathrm{Ca}^{2+}$ signal also play important roles in plant salt stress tolerance: $\mathrm{Na}^{+}$stress triggers cytosolic $\mathrm{Ca}^{2+}$-signal to activate SOS3 (in roots) or SCaBP8/CBL10 (in shoots) that interact with and activate a kinase, SOS2. The activated SOS2 phosphorylates and activates SOS1, a $\mathrm{Na}^{+} / \mathrm{H}^{+}$antiporter at the plasma membrane to pump $\mathrm{Na}^{+}$ out of cells, thus restoring ion homeostasis [20]. Another set of $\mathrm{Na}^{+} / \mathrm{H}^{+}$antiporters (NHXs) locate in vacuole membrane to facilitate $\mathrm{Na}^{+}$compartmentalization and maintain intracellular $\mathrm{K}^{+}$status [20]. CBF/DREB1s were also reported to be involved in plant salt tolerance as well. For example, overexpressing OsDREB1D and OsDREB1F improved plant salt tolerance in rice and/or Arabidopsis possibly by targeting genes involved in ionic and osmotic regulations $[8,9]$.

The PvDREB1C transgenic plants had significantly higher $\mathrm{Ca}^{2+}$ contents in leaves but not in roots, and $\mathrm{Ca}^{2+}$ activated the $\mathrm{Na}^{+} / \mathrm{H}^{+}$antiporters to exclude $\mathrm{Na}^{+}$from leaf cells, thereby reduced the ionic damage caused by $\mathrm{Na}^{+}$on the transgenic plants. At the transcription level, overexpressing 

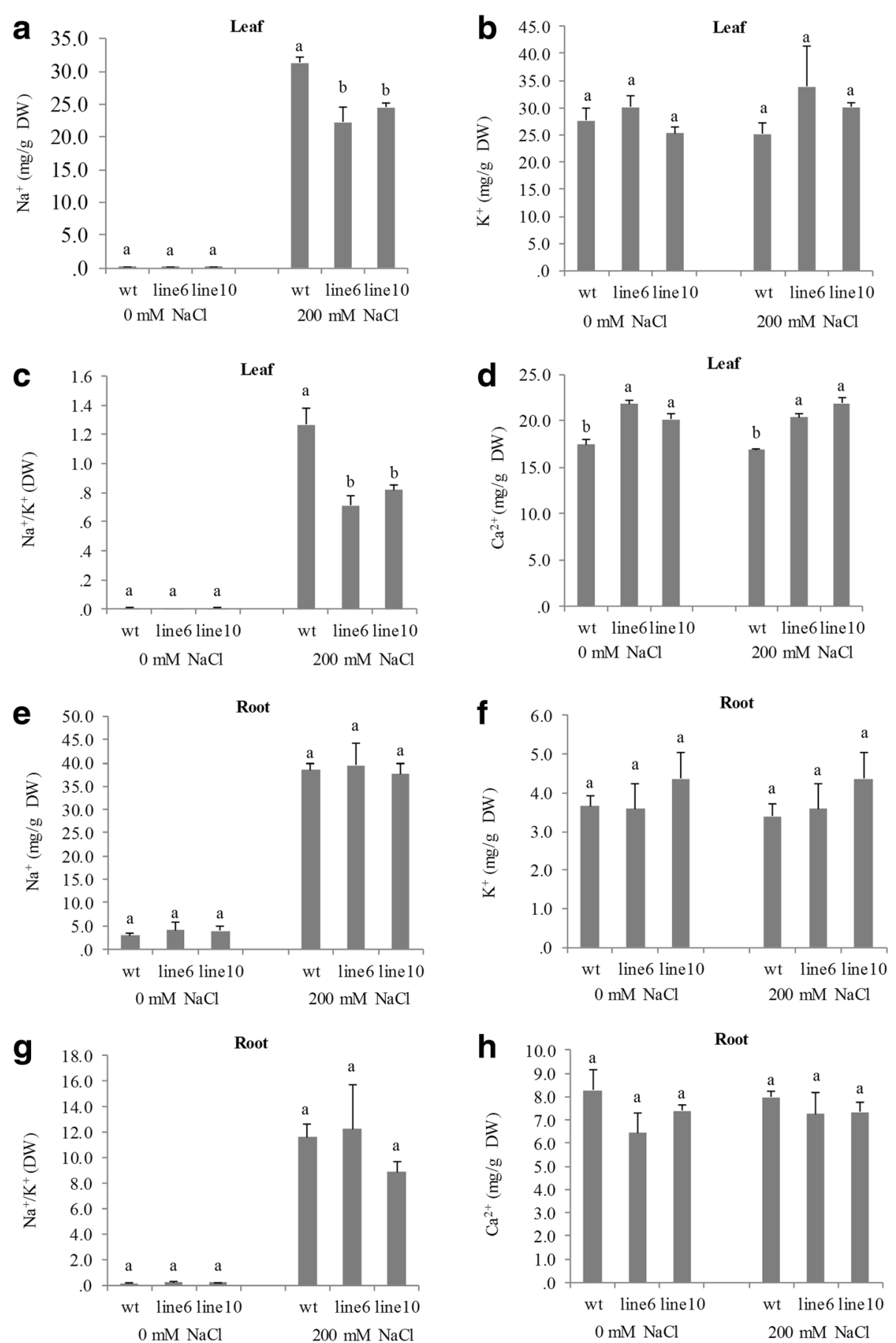

Fig. 5 Contents of $\mathrm{Na}^{+}, \mathrm{K}^{+}$and $\mathrm{Ca}^{2+}$, and ratios between $\mathrm{Na}^{+}$and $\mathrm{K}^{+}$in leaves $\mathbf{a}-\mathbf{d}$ or in roots $\mathbf{e}-\mathbf{h}$. Data are represented as mean $\pm \mathrm{SE}(n=6)$, and different letters above bars indicate a significant difference at $P<0.05$

PvDREB1C activated the expression of NtNHX4 which was involved in $\mathrm{Na}^{+}$compartmentalization [20], but not the expression of NtSOS1 which was responsible for pumping $\mathrm{Na}^{+}$out of the cell [20]. The low $\mathrm{Na}^{+} / \mathrm{K}^{+}$ratio in leaves of transgenic plants was probably due to altered expression of SOS genes in below-ground organs rather than in leaves which needs further investigation in the future. On the other hand, the PvDREB1C plants also had higher osmotic potential and less $\mathrm{H}_{2} \mathrm{O}_{2}$ accumulation, suggesting that PvDREB1C also functioned in activating osmoticregulation and ROS-scavenging systems under salt stress [14]. Yet, when subjected to chilling stress, the transgenic lines had higher EL suggesting that their plasma membranes were more vulnerable to cold. The exact reason 

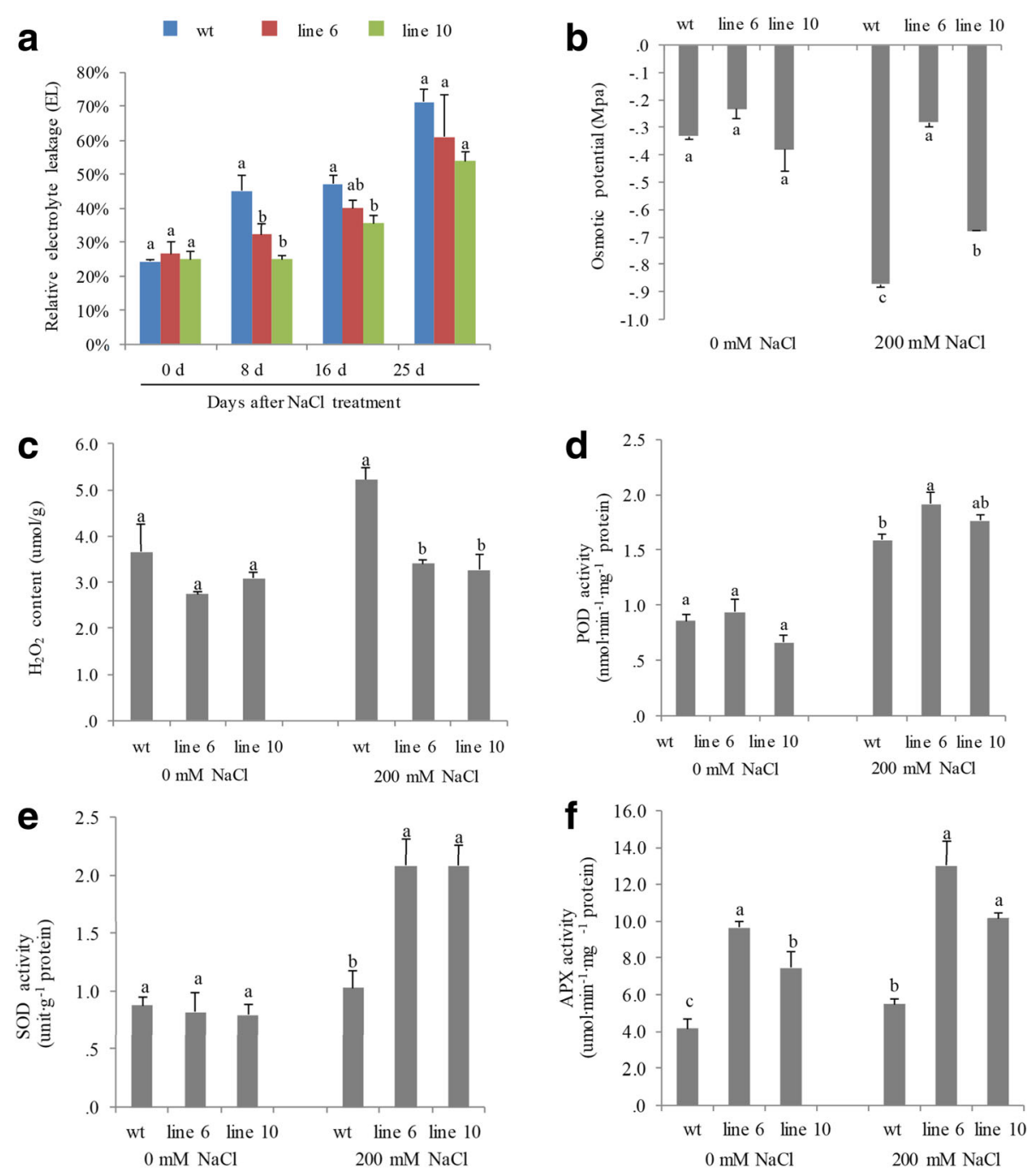

Fig. 6 Physiological responses of PVDREB1C transgenic and wildtype plants under salt stress. a Relative electrolyte leakage (EL) after the first watering with $\mathrm{NaCl}$. b-f Osmotic potential, $\mathrm{H}_{2} \mathrm{O}_{2}$ content, POD, SOD and APX activities in wildtype and transgenic plants 25 days after $\mathrm{NaCl}$ treatment. Data are represented as mean $\pm \mathrm{SE}(n=6)$, and different letters above bars indicate a significant difference at $P<0.05$

behind that difference needs to be further investigated in the future (e.g. by understanding the full picture of its downstream target gene networks).

Different DREBs have preference to the specific sequences of the core DRE cis-element. For examples, the rice CBF3/DREB1A bound to GCCGAC more preferentially than to ACCGAC, whereas the Arabidopsis CBF3/ DREB1A could efficiently bind to both GCCGAC and ACCGAC [11]. Flanking sequences of the DRE/CRT might also affect the binding efficiency of DREBs. For example, Maruyama et al. [24] found that CBF3 bounds to A/GCCGACNT more efficiently than to A/GCCGACNA/ G/C. Among the 302 inducible genes by low temperature in the wildtype Arabidopsis, 85 of them were induced by CBF2/DREB1C in transgenic Arabidopsis under normal growth temperature [25]. The $r d 29 A$ promoter has five conserved DRE cis-elements [26]. In this study, the conversion of ACCGAC to GCCGAC of the third upstream core DRE cis-element of $\bar{r} d 29 \mathrm{~A}$ promoter nearly abolished the transcriptional activation of PvDREB1C. Furthermore, among the four up-regulated downstream functional genes in $P v D R E B 1 C$ transgenic plants under salt stress, three of their $-2 \mathrm{~Kb}$ promoter regions (NtSOD, NtPOD, and $N t E R D 10 B)$ contain at least one ACCGAC sequences (see Additional file 1). Together, this result suggested that PvDREB1C preferentially activated those promoters with the core DRE cis-element of ACCGAC. Such information shall be useful for understanding the full picture of its downstream target gene networks using ChIP-seq and RNA-seq approaches in the future. 

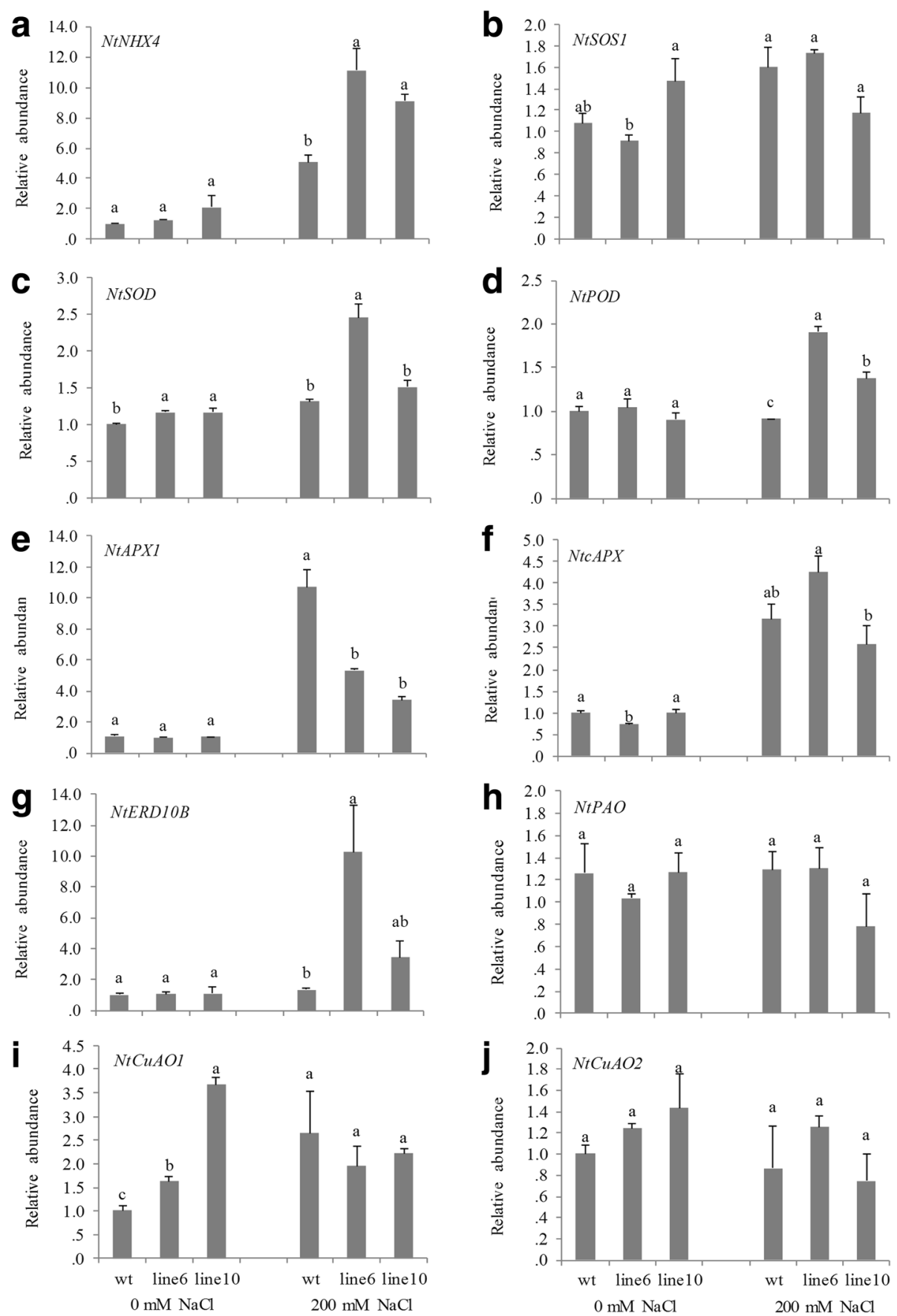

Fig. 7 Transcriptional changes of downstream functional genes encoding for ion transporters $\mathbf{a}$, $\mathbf{b}$, ROS-scavenging enzymes $\mathbf{c}-\mathbf{f}$, dehydrin and polyamines $\mathbf{g - j}$. Data are represented as mean \pm SE $(n=3)$, and different letters above bars indicate a significant difference at $P<0.05$

\section{Conclusions}

It is inevitable to grow switchgrass in barren, saline and other types of marginal land for the purposes of biofuel and forage feedstock crop production and water and soil conservation. The current results showed that PvDREB1C played opposite roles in cold and salt tolerance, and supported that PvDREB1C could be used for improving switchgrass salt tolerance, but particular attentions shall be paid to its negative role in cold tolerance.

\section{Methods}

Plant materials

Switchgrass line 'HR8' [27] selected from the ecotype 'Alamo' was used to study the PvDREB1s expression levels. The plant growth condition was the same as previously 


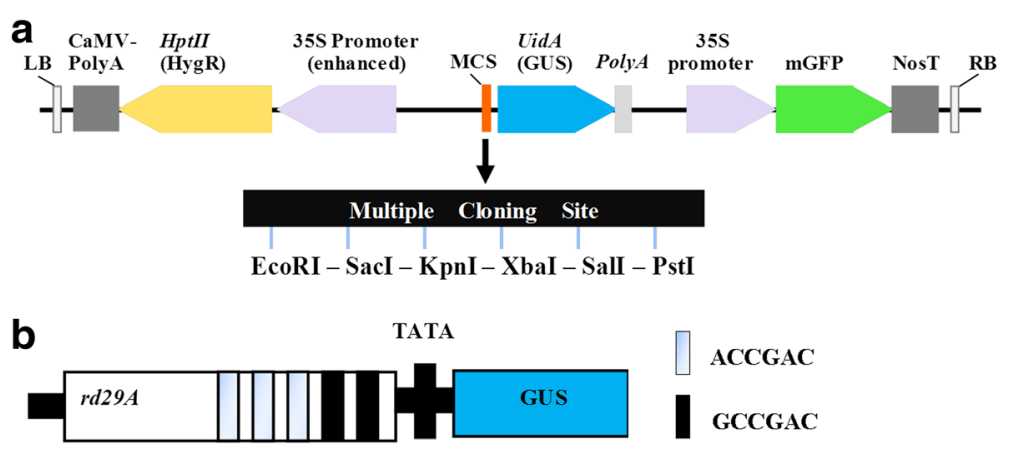

GUS activity

(umol 4-MU/mg protein /min)

C

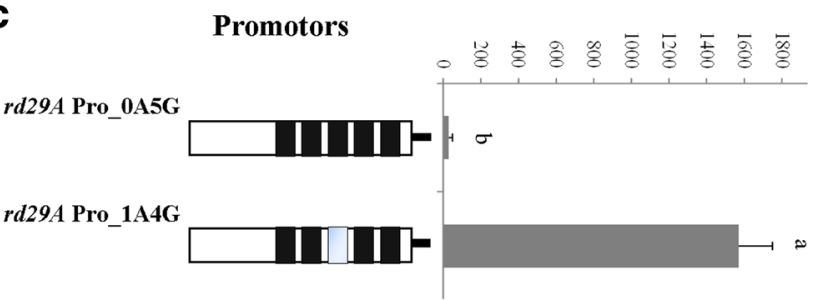

Fig. 8 PVDREB1C activated rd29A promoter. a The pCAMBIA1302-Pro: GUS-polyA vector constructed for promoter analysis. b Activation of rd2OA:GUS reporter gene by PVDREB1C as measured with the activity of GUS. Data are represented as mean \pm SE $(n=15)$, and different letters above bars indicate a significant difference at $P<0.05$

reported with a $14 \mathrm{~h}$ photoperiod and the growth temperature set at $30 / 20 \pm 3{ }^{\circ} \mathrm{C}$ (day/night) [28].

The tobacco (Nicotiana tabacum and N. benthamiana) plants were grown in pots with peat soil, and were maintained in growth chambers set at $23 / 20{ }^{\circ} \mathrm{C}$ (day/ night) with a $12 \mathrm{~h}$ photoperiod and photoactive radiation of $350 \mu \mathrm{mol}$ photons $\mathrm{m}^{-2} \cdot \mathrm{s}^{-1}$ for 4 weeks.

\section{Gene cloning and vector construction}

Putative cold-inducible DREB1 (PvDREB1s) genes were pooled out from the switchgrass genome database (Panicum virgatum v1.1, DOE-JGI) that were homologous to four rice cold-responsive OsDREB1 genes. These PvDREB1s were named as DREB1A-1 (Pavir.J03891.1), DREB1A-2 (Pavir.Ba01280.1), DREB1B-1 (Pavir.J19655.1), DREB1B-2 (Pavir.Ba01283.1), DREB1C (Pavir.J35991.1), DREB1G-1 (Pavir.Ab02685.1), DREB1G-2 (Pavir.Aa00912.1) and were amplified by PCR using the Q5 PCR mix (New England Biolabs, Beverly, MA) with the annealing temperature set at $61{ }^{\circ} \mathrm{C}$ for 30 amplification cycles. The gene was cloned into an entry vector and then to the plant expression vector pEarlyGate103 [29].

The pCAMBIA1302-Pro:GUS-polyA vector was constructed for promoter analysis. In brief, the GUS-polyA fragment was amplified by PCR from the pCAMBIA1305.1 vector with the flanking PstI \& HindIII sites, cloned into pENTR/D vector, and sequenced. Then the fragment was inserted into the corresponding restriction enzyme sites of pCAMBIA1302. The resultant pCambia1302-Pro:GUS-
polyA vector has a number of restriction enzyme sites (EcoRI - SacI - KpnI - XbaI - SalI - PstI) upstream of the GUS (UidA) gene for the insertion of target promoter.

The $r d 29 A$ (AT5G52310) promoter was cloned from Arabidopsis ecotype 'Columbia', and sequenced. Mutations were introduced into the DRE/CRT cis-element to result in A/GCCGAC (sequences as shown in data S1). These five promoters were sub-cloned into the EcoRI \& KpnI sites of pCAMBIA1302-Pro:GUS-polyA.

\section{Switchgrass stress treatment and qRT-PCR analysis}

The switchgrass plantlets at the height of $\sim 30 \mathrm{~cm}$ were used for the following treatments. In brief, three fully expanded leaves (the 3rd leaves from the top) from different plantlets were pooled as one sample, and the sampling time were set at $0,0.5,1,2,4,8,12$ and $24 \mathrm{~h}$ after cold $\left(4{ }^{\circ} \mathrm{C}\right)$, $20 \%$ PEG, or $250 \mathrm{mM} \mathrm{NaCl}$ treatment, respectively.

The total RNA was isolated from switchgrass leaves using RNApure fast isolation Kit (YuanPingHao, Tianjin, China). The first strand cDNA was synthesized with $1 \mu \mathrm{g}$ RNA using the PrimeScript ${ }^{\mathrm{RT}}$ Reagent Kit after the removal of gDNA (Takara, Dalian, China). The qRT-PCR was performed on a Roche LightCycler480 II machine (Roche Diagnostic, Rotkreuz, Switzerland) using the SYBR Green I Master Reaction System (Roche Diagnostic). The PCR condition was set as follows: $10 \mathrm{~min}$ at $95{ }^{\circ} \mathrm{C}$ for initial denaturation, and 40 cycles of PCR $\left(95^{\circ}\right.$ $\mathrm{C}$ for $15 \mathrm{~s}, 58^{\circ} \mathrm{C}$ for $15 \mathrm{~s}$, and $72{ }^{\circ} \mathrm{C}$ for $20 \mathrm{~s}$ ). Three biological replicates and two technical replicates were 
performed. Relative expression levels were calculated using the $2^{-\triangle \Delta C T}$ method with PvFTSH4 as a reference gene [30]. The qRT-PCR primers used in this study were shown in Table 1.

\section{Tobacco genetic transformation and transient assay}

All binary vectors used in this study were electrotransformed into the Agrobacterium tumefaciens strain 'AGL1'. The genetic transformation of tobacco was conducted as previously described [31]. The transgenic plants were screened by $15 \mathrm{mg} \cdot \mathrm{L}^{-1}$ bialaphos and the regenerated plants, once rooted in soil, were verified by PCR.

The relative binding efficiency of PvDREB1C to the above described five $r d 29 \mathrm{~A}$ promotors was tested using a transient assay method on mature leaves of 4-week-old $N$. benthamina plants. In brief, pEarleyGate103-PvDREB1c/ AGL1 and pCAMBIA1302-RD29A_Pro: GUS-polyA/
AGL1 were mixed together, and co-injected into tobacco leaves. The amount of injected solution was measured using a labelled syringe and was kept the same for all treatments. The empty vector, pCAMBIA1302-Pro:GUSpolyA without any promoter upstream of the UidA (GUS) gene, was used as the negative control. Leaves injected with the infection solution (1/2 MS, 3\% sucrose and $100 \mu \mathrm{M}$ acetosyringone, $\mathrm{pH}$ 5.7) were used as background controls. Each testing point was measured with 15 biological replicates. After $24 \mathrm{~h}$, the injected leaves were sampled and measured for GUS activity using a method as described by Fior et al. [32].

\section{Evaluation of transgenic plants exposed to low temperature and salt stress}

One and a half month old T2 transgenic and wildtype tobaccos were grown in pots and used for cold and freezing tolerance analysis: (1) for $4{ }^{\circ} \mathrm{C}$ cold tolerance, 18

Table 1 Primers used in this study

\begin{tabular}{|c|c|c|c|}
\hline Primer sets & NCBI Accession No. for the target gene & Primer Sequence $\left.\left(5^{\prime}-3^{\prime}\right)\right)$ & Purpose \\
\hline \multirow[t]{2}{*}{ PVDREB1C_CDS } & \multirow[t]{2}{*}{ Pavir.J35991.1 } & ATACGGATCATGGAGTACGACGAGCAGGAG & \multirow[t]{2}{*}{ Cloning of PVDREB1C } \\
\hline & & TGATAAGCTTGTCGTAGTAGCTCCACAGCGTC & \\
\hline \multirow[t]{2}{*}{ 35S_F1 \& GFP_R1 } & \multirow[t]{2}{*}{-} & TCCACTGACGTAAGGGATGAC & \multirow[t]{2}{*}{ PCR verification of transgenic tobacco } \\
\hline & & AGAATTGGGACAACTCCAGTG & \\
\hline \multirow[t]{2}{*}{$P \vee D R E B T C \_q R T$} & \multirow[t]{2}{*}{ Pavir.J35991.1 } & GGAGTACGACGAGCAGGAGT & \multirow[t]{2}{*}{ qRT-PCR } \\
\hline & & GGTCTCCCGGAACTTGGT & \\
\hline \multirow[t]{2}{*}{ NtSOD } & \multirow[t]{2}{*}{ AB093097 } & AGCTACATGACGCCATTTCC & \multirow[t]{2}{*}{ qRT-PCR } \\
\hline & & CCCTGTAAAGCAGCACCTTC & \\
\hline \multirow[t]{2}{*}{ NtPOD } & \multirow[t]{2}{*}{ D11396.1 } & GCTGTTCGACGAGTTGTTAACAG & \multirow[t]{2}{*}{ qRT-PCR } \\
\hline & & CTCTGGCTGAGTTGTTGTTGG & \\
\hline \multirow[t]{2}{*}{ NtAPX1 } & \multirow[t]{2}{*}{ AU15933 } & CAAATGTAAGAGGAAACTCAGAGGA & \multirow[t]{2}{*}{ qRT-PCR } \\
\hline & & CAGCCTTGAGCCTCATGGTACCG & \\
\hline \multirow[t]{2}{*}{ NtCAPX } & \multirow[t]{2}{*}{ D85912 } & CTGGAGTTGTTGCTGTTG & \multirow[t]{2}{*}{ qRT-PCR } \\
\hline & & GGTGGCTCTGTCTTGTC & \\
\hline \multirow[t]{2}{*}{ NtNHX4 } & \multirow[t]{2}{*}{ XM_016617731 } & CAAGAACTTCCGCACCCAC & \multirow[t]{2}{*}{ qRT-PCR } \\
\hline & & GCAGTATCAAACGCAGAGGACC & \\
\hline \multirow[t]{2}{*}{ NtSOS1 } & \multirow[t]{2}{*}{ XM_016611194 } & CAAATGTTATCCCCCGAAAGC & \multirow[t]{2}{*}{ qRT-PCR } \\
\hline & & CGGAGAACCTGAGGAAATGTGA & \\
\hline \multirow[t]{2}{*}{ NtERD10B } & \multirow[t]{2}{*}{ AB049336 } & CAATTAGTGCAGGCCAGGC & \multirow[t]{2}{*}{ qRT-PCR } \\
\hline & & GGTCCATGGTGGCCAGGAAG & \\
\hline \multirow[t]{2}{*}{ NtPAO } & \multirow[t]{2}{*}{ AB200262 } & GCTGCTCTGTCGTCATA & \multirow[t]{2}{*}{ qRT-PCR } \\
\hline & & TATCCTGCCACCTATCTTATC & \\
\hline NtCuAO1 & DQ873385 & TATGGCAGTTGATTGTAAGC & qRT-PCR \\
\hline & & TGACGAGCAGAGAATGG & \\
\hline NtCuAO2 & AB289457 & TATGGCAGTTGATTGTAAGC & qRT-PCR \\
\hline & & CCAATGACGAGCAGATAAAGT & \\
\hline NtUbiquitin & XM_016580871 & TCCAGGACAAGGAGGGTAT & qRT-PCR \\
\hline & & CATCAACAACAGGCAACCTAG & \\
\hline
\end{tabular}


plants of each line were moved into one growth chamber with temperature set at $4{ }^{\circ} \mathrm{C}$ and under light of $200 \mu \mathrm{mol}$ photon $\mathrm{m}^{-2} \mathrm{~s}^{-1}$ for $24 \mathrm{~h}$; (2) for freezing tolerance, another batch of tobacco plants (18 plants of each line) were moved to the growth chamber with temperature gradually decreased to $-4{ }^{\circ} \mathrm{C}$ (lowering two degrees per hour starting from $4{ }^{\circ} \mathrm{C}$ ), and maintained at $-4{ }^{\circ} \mathrm{C}$ for $3 \mathrm{~h}$. The plants were then moved back to optimum growth condition and their survival rates were counted after recovery for $2 \mathrm{~d}$ [33].

T2 transgenic plants were used for the salt tolerance. One and a half month old tobacco plants grown in pots were also used for salt tolerance assessment by watering with $200 \mathrm{mM} \mathrm{NaCl}$ for 25 days. Plants normally watered were used as controls.

\section{Measurement of physiological parameters Electrolyte leakage}

The leaf electrolyte leakage (EL) was measured according to Jiang and Huang [34]. In brief, leaves at the same positions were detached and incubated in $30 \mathrm{ml}$ distilled deionized water. The initial level of EL $\left(C_{i}\right)$ was measured using a conductance meter (Thermo Scientific, Baverly, USA) after shaken for $24 \mathrm{~h}$ at room temperature. The leaf tissue was then killed in an autoclave at $121{ }^{\circ} \mathrm{C}$ for $30 \mathrm{~min}$, and incubated for $24 \mathrm{~h}$ on a shaker for measuring the maximum conductance $\left(\mathrm{C}_{\max }\right)$ of the incubation solution. Relative EL was calculated as $\mathrm{EL}=\left(\mathrm{C}_{\mathrm{i}} / \mathrm{C}_{\max }\right) \times 100$.

\section{Osmotic potential}

Osmatic potential was measured using an osmatic potential determinator Vapro Model 5520 (Wescor, Logan, Utah). The leaf tissue was soaked in distilled water for $6 \mathrm{~h}$, then in liquid nitrogen for $1 \mathrm{~min}$, and on ice for another $30 \mathrm{~min}$. Finally, the leaves were ground into juice for measurement.

\section{$\mathrm{H}_{2} \mathrm{O}_{2}$ content}

The $\mathrm{H}_{2} \mathrm{O}_{2}$ content was measured according to Sergiev [35]. In brief, seedlings were extracted with $2 \mathrm{ml}$ cold 5\% $(w / v)$ TCA. The extraction was then centrifuged at 12,054 $\mathrm{g}$ for $15 \mathrm{~min}$. The $0.5 \mathrm{ml}$ supernatant was mixed with $0.5 \mathrm{ml} \mathrm{PBS} \mathrm{(0.1} \mathrm{M,} \mathrm{pH} \mathrm{7.0)} \mathrm{and} 1 \mathrm{ml} \mathrm{KI} \mathrm{(1} \mathrm{M),} \mathrm{and}$ then incubated at room temperature in the dark for $1 \mathrm{~h}$. The absorbance of the mixture was measured at $390 \mathrm{~nm}$ and the concentration of $\mathrm{H}_{2} \mathrm{O}_{2}$ was calculated against the standard curve.

\section{SOD, POD and APX activities}

A total of $0.2 \mathrm{~g}$ leaves were ground in $4 \mathrm{ml}$ extracting solution ( $3 \mathrm{ml} 50 \mathrm{mM}$ PH7.8 PBS and $1 \mathrm{ml} 1 \mathrm{mM}$ EDTA.2Na) and the homogenate was centrifuged at $15,000 \mathrm{~g}$ for 30 min at $4{ }^{\circ} \mathrm{C}$, the supernatant was collected for enzyme activity analysis. The activities of SOD, POD and APX were measured by spectrophotometry according to the method described by Giannopolitis et al. [36], Zheng et al. [37] and Hossain et al. [38], respectively.

\section{$\mathrm{Na}^{+}, \mathrm{K}^{+}$and $\mathrm{Ca}^{2+}$ contents}

The leaves and roots of transgenic plants and wildtype treated with or without $200 \mathrm{mM} \mathrm{NaCl}$ were used for the $\mathrm{Na}^{+}, \mathrm{K}^{+}$and $\mathrm{Ca}^{2+}$ content measurement according to Shukla et al. [39].

\section{Statistical analysis}

Data in this study were statistically analyzed using one-way ANOVA, and the means were compared by Duncan test at a significance level of 0.05 by using SPSS (version 12, SPSSInc., Chicago, IL, USA). Data were shown as mean \pm SE. Different letters above the bar in figures represented statistically significant difference at the level of 0.05 .

\section{Additional file}

Additional file 1: The mutated sequences of $r d 29 \mathrm{~A}$ promoter used in this study. (XLSX 26 kb)

\section{Abbreviations}

APX: Ascorbate peroxidase; CBFs: C-repeat-binding factors; DRE: Dehydrationresponsive element; DREB: Dehydration-responsive element binding factor; EDTA: Ethylenediaminetetraacetic acid; EL: Electrolyte leakage;

PBS: Phosphate buffer saline; POD: Peroxidase; SOD: Superoxide dismutase; TCA: Trichloroacetate

\section{Acknowledgments}

The authors thank the funding agencies and Drs. Zhimin Yang and Lili Zhuang for their assistance in lab and green house management.

Funding

This study was supported by the Student Research Training project 201610307018Y, and by grant KYZ201552 from the Fundamental Research Funds for the Central Universities.

\section{Availability of data and materials}

The datasets supporting the conclusions and methods description are included within the article.

\section{Authors' contributions}

WW, ZX, GY, CZ and ZY performed the experiments, WW, LH, BX, and BH analyzed the data, and wrote the manuscript; $L H$ and BX designed the experiments; and all authors approved the manuscript.

Ethics approval and consent to participate

All authors read and approved the manuscript.

Consent for publication

All authors agreed to publish this manuscript.

Competing interests

The authors declare that they have no competing interests.

\section{Publisher's Note}

Springer Nature remains neutral with regard to jurisdictional claims in published maps and institutional affiliations. 


\section{Author details}

College of Agro-grassland Science, Nanjing Agricultural University, Nanjing 210095, People's Republic of China. 'Department of Grassland Science, Animal Science and Technology College, Sichuan Agricultural University, Ya'an, Sichuan 625014, People's Republic of China. ${ }^{3}$ Department of Plant Biology and Pathology, Rutgers, the State University of New Jersey, New Brunswick, NJ 08901, USA

\section{Received: 10 August 2017 Accepted: 9 October 2017}

\section{Published online: 24 October 2017}

\section{References}

1. Sanderson MA, Read JC, Reed RL. Harvest management of switchgrass for biomass feedstock and forage production. Agron J. 1999;91:5-10.

2. Sanderson M, Reed R, McLaughlin S, Wullschleger S, Conger B, Parrish D, Wolf D, Taliaferro C, Hopkins A, Ocumpaugh W. Switchgrass as a sustainable bioenergy crop. Bioresour Technol. 1996;56:83-93.

3. Nelson RG, Ascough JC, Langemeier MR. Environmental and economic analysis of switchgrass production for water quality improvement in northeast Kansas. J Environ Manag. 2006:79:336-47.

4. Casler MD, Vogel KP, Taliaferro CM, Wynia RL. Latitudinal adaptation of Switchgrass populations this research was funded in part by the U.S. Dep. Of energy biomass fuels program via the oak ridge National lab. Contract no. DE-A105-900R2194. Crop Sci. 2004:44:293-303.

5. Yamaguchi-Shinozaki K, Shinozaki K. Transcriptional regulatory networks in cellular responses and tolerance to dehydration and cold stresses. Annu Rev Plant Biol. 2006;57:781-803.

6. Liu Q, Kasuga M, Sakuma Y, Abe H, Miura S, Yamaguchi-Shinozaki K, Shinozaki K. Two transcription factors, DREB1 and DREB2, with an EREBP/ AP2 DNA binding domain separate two cellular signal transduction pathways in drought-and low-temperature-responsive gene expression, respectively, in Arabidopsis. Plant Cell. 1998;10:1391-406.

7. Chinnusamy V, Zhu J, Zhu J-K. Cold stress regulation of gene expression in plants. Trends Plant Sci. 2007;12:444-51

8. Wang Q, Guan Y, Wu Y, Chen H, Chen F, Chu C. Overexpression of a rice OsDREB1F gene increases salt, drought, and low temperature tolerance in both Arabidopsis and rice. Plant Mol Biol. 2008:67:589-602.

9. Zhang $Y$, Chen $C$, Jin XF, Xiong AS, Peng RH, Hong YH, Yao QH, Chen JM. Expression of a rice DREB1 gene, OsDREB1D, enhances cold and high-salt tolerance in transgenic Arabidopsis. BMB Rep. 2009;42:486-92.

10. Mao D, Chen C. Colinearity and similar expression pattern of Rice DREB1s reveal their functional conservation in the cold-responsive pathway. PLoS One. 2012;7:-e47275

11. Dubouzet JG, Sakuma Y, Ito Y, Kasuga M, Dubouzet EG, Miura S, Seki M, Shinozaki K, Yamaguchi-Shinozaki K. OsDREB genes in rice, Oryza sativa L. encode transcription activators that function in drought-, high-salt- and cold-responsive gene expression. Plant J. 2003;33:751-63.

12. Yuan $\mathrm{S}, \mathrm{Xu}$ B, Zhang J, Xie Z, Cheng Q, Yang Z, Cai Q, Huang B. Comprehensive analysis of CCCH-type zinc finger family genes facilitates functional gene discovery and reflects recent allopolyploidization event in tetraploid switchgrass. BMC Genomics. 2015;16:129.

13. Huang S, Su X, Haselkorn R, Gornicki P. Evolution of switchgrass (Panicum virgatum L.) based on sequences of the nuclear gene encoding plastid acetyl-CoA carboxylase. Plant Sci. 2003:164:43-9.

14. Munns R, Tester M. Mechanisms of salinity tolerance. Annu Rev Plant Biol. 2008:59:651-81.

15. Agarwal PK, Agarwal P, Reddy M, Sopory SK. Role of DREB transcription factors in abiotic and biotic stress tolerance in plants. Plant Cell Rep. 2006; 25:1263-74.

16. Gilmour SJ, Zarka DG, Stockinger EJ, Salazar MP, Houghton JM, Thomashow MF. Low temperature regulation of the Arabidopsis CBF family of AP2 transcriptional activators as an early step in cold-induced COR gene expression. Plant J. 1998;16:433-42.

17. Qin QL, Liu JG, Zhang Z, Peng RH, Xiong AS, Yao QH, Chen JM. Isolation, optimization, and functional analysis of the CDNA encoding transcription factor OsDREB1B in Oryza Sativa L. Mol Breed. 2007;19:329-40.

18. Novillo F, Alonso JM, Ecker JR, Salinas J. CBF2/DREB1C is a negative regulator of CBF1/DREB1B and CBF3/DREB1A expression and plays a central role in stress tolerance in Arabidopsis. P Natl Acad Sci USA. 2004;101:3985-90.
19. Ishizaki T, Maruyama K, Obara M, Fukutani A, Yamaguchi-Shinozaki K, Ito Y Kumashiro T. Expression of Arabidopsis DREB1C improves survival, growth and yield of upland new Rice for Africa (NERICA) under drought. Mol Breed. 2013;31:255-64.

20. Zhu JK. Abiotic stress signaling and responses in plants. Cell. 2016;167:313-24.

21. Huang B, Dacosta M, Jiang Y. Research advances in mechanisms of Turfgrass tolerance to Abiotic stresses: from physiology to molecular biology. Crit Rev Plant Sci. 2014;33:141-89.

22. Sangwan V, Orvar BL, Beyerly J, Hirt H, Dhindsa RS. Opposite changes in membrane fluidity mimic cold and heat stress activation of distinct plant MAP kinase pathways. Plant J. 2002:31:629-38.

23. Ding $Y$, Li H, Zhang X, Xie Q, Gong Z, Yang S. OST1 kinase modulates freezing tolerance by enhancing ICE1 stability in Arabidopsis. Dev Cell. 2015;32:278-89.

24. Maruyama K, Sakuma Y, Kasuga M, Ito Y, Seki M, Goda H, Shimada Y, Yoshida S, Shinozaki K, Yamaguchi-Shinozaki K. Identification of coldinducible downstream genes of the Arabidopsis DREB1A/CBF3 transcriptional factor using two microarray systems. Plant J. 2004;38:982-93.

25. Vogel JT, Zarka DG, Buskirk HAV, Fowler SG, Thomashow MF. Roles of the CBF2 and ZAT12 transcription factors in configuring the low temperature transcriptome of Arabidopsis. Plant J. 2005:41:195-211.

26. Yamaguchi-Shinozaki K, Shinozaki K. A novel cis-acting element in an Arabidopsis gene is involved in responsiveness to drought, lowtemperature, or high-salt stress. Plant Cell. 1994;6:251-64.

27. Xu B, Huang L, Shen Z, Welbaum GE, Zhang X, Zhao B. Selection and characterization of a new switchgrass (Panicum virgatum L.) line with high somatic embryogenic capacity for genetic transformation. Sci HortAmsterdam. 2011;129:854-61.

28. Xu B, Sathitsuksanoh N, Tang Y, Udvardi MK, Zhang JY, Shen Z, Balota M, Harich K, Zhang PY, Zhao B. Overexpression of AtLOV1 in switchgrass alters plant architecture, lignin content, and flowering time. PLoS one. 2012;7:e47399.

29. Earley KW, Haag JR, Pontes O, Opper K, Juehne T, Song K, Pikaard CS. Gateway-compatible vectors for plant functional genomics and proteomics. Plant J. 2006;45:616-29.

30. Gimeno J, Eattock N, Van Deynze A, Blumwald E. Selection and validation of reference genes for gene expression analysis in switchgrass (Panicum virgatum) using quantitative real-time RT-PCR. PLoS One. 2014:9:e91474.

31. Horsch R, Fry J, Hoffmann N, Eichholtz D, Rogers S, Fraley R. A simple and general method for transferring genes into plants. Science. 1985;227:1229-31.

32. Fior S, Vianelli A, Gerola PD. A novel method for fluorometric continuous measurement of $\beta$-glucuronidase (GUS) activity using 4-methyl-umbelliferyl$\beta$ - $d$-glucuronide (MUG) as substrate. Plant Sci. 2009;176:130-5.

33. Zhuo C, Wang T, Lu S, Zhao Y, Li X, Guo Z. A cold responsive galactinol synthase gene from Medicago Falcata (MfGolS1) is induced by myoinositol and confers multiple tolerances to abiotic stresses. Plant Physiol. 2013;149:67-78

34. Jiang $Y$, Huang B. Physiological responses to heat stress alone or in combination with drought: a comparison between tall fescue and perennial ryegrass. HortSci. 2001;36:682-6.

35. Sergiev I, Alexieva V, Karanov E. Effect of spermine, atrazine and combination between them on some endogenous protective systems and stress markers in plants. Compt Rend Acad Bulg Sci. 1997:51:121-4.

36. Giannopolitis CN, Ries SK. Superoxide dismutase: I. Occurrence in higher plants. Plant Physiol. 1977;59:309-14.

37. Zheng $X$, Huystee RBV. Peroxidase-regulated elongation of segments from peanut hypocotyls. Plant Sci. 1992:81:47-56

38. Hossain MA, Asada K. Inactivation of Ascorbate Peroxidase in spinach chloroplasts on dark addition of hydrogen peroxide: its protection by Ascorbate. Plant Cell Physiol. 1984:25:1285-95.

39. Shukla PS, Agarwal PK, Jha B. Improved salinity tolerance of Arachis hypogaea (L.) by the interaction of halotolerant plant-growth-promoting rhizobacteria. J Plant Growth Regul. 2011;31:195-206. 